\title{
VARIATION OF MICROSTRUCTURE WITH CARBONATION IN LIME AND BLENDED PASTES
}

$\mathbf{N}^{0}$ of pages: 32

$\mathbf{N}^{0}$ of tables: 8

$\mathbf{N}^{0}$ of figures: 5

PACS Codes: $81.05 . \mathrm{Rm} \quad 68.43 . \mathrm{h}$

Keywords: Lime pastes, blended pastes, carbonation, pore size distribution, surface fractal dimension, $\mathrm{W} / \mathrm{B}$ ratio

Please, send all correspondence to:

Dr. José I. Alvarez Galindo

Dpto. de Química

Fac. de Ciencias

Universidad de Navarra

$\mathrm{C} /$ Irunlarrea $\mathrm{s} / \mathrm{n}$

31.080 Pamplona (Navarra)

Spain

Phone: 34948425600

Fax: 34948425649

E-mail: jalvarez@unav.es 


\title{
VARIATION OF MICROSTRUCTURE WITH CARBONATION IN LIME AND BLENDED PASTES
}

\author{
M. Arandigoyen ${ }^{\text {a }}$, B. Bicer-Simsir ${ }^{\text {b }}$, J.I. Alvarez ${ }^{\text {a, }}{ }^{\text {, D.A. Lange }}{ }^{\mathrm{b}}$ \\ ${ }^{a}$ Departamento de Química, Universidad de Navarra, 31080 Pamplona, Spain \\ ${ }^{b}$ Department of Civil and Environmental Engineering, University of Illinois, Urbana, \\ IL 61801, USA
}

\begin{abstract}
:
Carbonation, as a reaction of the curing process of both, cement and lime binders, modifies the microstructure. Several microstructure properties, namely, porosity, pore size distribution, surface fractal dimension and specific surface area have been investigated in this study to describe the effect of carbonation on microstructure. Both carbonated and non-carbonated pastes of lime and blended pastes of lime and cement having varying W/B (water/binder) ratios are studied. Results show that carbonation decreases the porosity, but not with the same intensity in all pore size ranges. The highest modification is between 0.03 and $0.01 \mu \mathrm{m}$ in lime pastes and between 0.2 and $0.02 \mu \mathrm{m}$ in $50 \%$ lime pastes, while in $80 \%$ lime pastes the modification is very small. It is also observed that carbonation is a function of the binder composition but not of the W/B ratio. Moreover, surface fractal dimension decreases during the carbonation process, while the specific surface area varies depending of the binder composition.
\end{abstract}

PACS Codes: 81.05.Rm 68.43.h

Keywords: Lime pastes, blended pastes, carbonation, pore size distribution, surface fractal dimension, $\mathrm{W} / \mathrm{B}$ ratio 


\section{Introduction}

As it is well known, carbonation, a consequence of the transformation of $\mathrm{Ca}(\mathrm{OH})_{2}$ to $\mathrm{CaCO}_{3}$, causes variation of the microstructure of mortars and concretes by decreasing their porosity. Carbonation also causes the change of material properties that are closely related to the microstructure, such as permeability, diffusivity of gases, capillarity, etc... Several authors have studied the variation of material properties with carbonation process: Ngala [1] investigated the effects of carbonation on pore structure and diffusional properties of hydrated cement pastes. Johannesson and Utgenannt [2] studied the change of specific surface area of cement mortar using BET theory. As a result of comparing carbonated and non-carbonated cement pastes, Houst [3] observed that the amount of water adsorbed decreased with carbonation. Dias [4] analyzed the reduction of concrete sorptivity with carbonation. Rodríguez-Navarro et al. [5] studied the formation of Liesegang rings (concentric $\mathrm{CaCO}_{3}$ and $\mathrm{Ca}(\mathrm{OH})_{2}$ non-carbonated alternatively) in lime mortars as a consequence of the carbonation process. Bertos et al. [6] discussed the variations of different properties (permeability, porosity, tortuosity, and pore size distribution) as a consequence of the carbonation process in cement based materials.

Most of the previous works have been done on the effect of carbonation of cement paste or mortar. But in the present paper, lime paste and blended (lime/cement) pastes have been considered. In order to understand the effect of carbonation on pore system, in addition to measuring total porosity and surface area changes, the change of the pores sizes and surface (texture) of the pores is studied, through the surface fractal dimension. The study has been carried out in lime pastes and blended pastes of lime and cement, both of them with different W/B ratios. Therefore, in the present work, the variation of 
the microstructure due to the carbonation process has been studied taking into account the variation of the composition of the binder and the W/B ratio.

\section{Carbonation Process}

During the carbonation, portlandite crystals, $\mathrm{Ca}(\mathrm{OH})_{2}$, reacts with $\mathrm{CO}_{2}$ and forms calcite crystals, $\mathrm{CaCO}_{3}$. Since calcite crystals have different crystal structure and molar volume, the microstructure of the lime and lime-cement pastes changes, such as, crystals join to each other creating a net and the strength of the material increases.

$$
\mathrm{Ca}(\mathrm{OH})_{2}+\mathrm{CO}_{2} \leftrightarrow \mathrm{CaCO}_{3}+\mathrm{H}_{2} \mathrm{O}
$$

Although carbonation process is defined as a "single" chemical reaction (Eq. 1), there are several stages take place: i) the $\mathrm{CO}_{2}$ diffuse through the paste, being influenced by the microstructure and by the water content [7]; ii) the $\mathrm{CO}_{2}$ is dissolved in the pore water (Henry's law); iii) the chemical equilibrium of $\mathrm{CO}_{2}$ in water takes place; iv) the $\mathrm{Ca}(\mathrm{OH})_{2}$ is dissolved in the water, being influenced by the specific surface area and by the amount of water and the microstructure of the paste, specially the complexity of the surface of the walls of the pores [5]; v) the precipitation of $\mathrm{CaCO}_{3}$ takes place; vi) the $\mathrm{H}_{2} \mathrm{O}$ as product of the reaction is desorbed.

In this process two kinds of factors can predominate: Kinetic or thermodynamic factors. If kinetic factors predominate, $\mathrm{CaCO}_{3}$ will precipitate as aragonite or as vaterite, both of these polymorphs will convert finally into calcite, the more stable polymorph [8]. If thermodynamic factor predominates $\mathrm{CaCO}_{3}$ will precipitate as calcite. As it is shown in Table 1, the porosity of the paste will vary depending on the polymorph formed, although, finally, all the polymorphs will revert to calcite [8]. 
Finally, the equilibrium between the relative humidity of the environment and the water produced in the first reaction (Eq.1) (the water content in the paste) is established. After the equilibrium is reached, the water produced in the reaction will evaporate.

\section{Experimental Procedure}

\subsection{Pastes Preparation}

A hydrated commercial lime powder $\left(\right.$ Ecobat $\left.^{\circledR}\right)$ (supplied by Calinsa S.A, Navarra, of the class CL90 according to Spanish standard [10]) and a portland cement CEM II-A/L 32.5 (according to the Spanish standard [11]) were used. Nine pastes having different lime and cement contents and W/B ratios (weight/weight) were prepared following the compositions given in Table 2.

The pastes were noted according to the different W/B ratio for each composition Pastes $\mathrm{A}, \mathrm{B}$ and $\mathrm{C}$ represent the lowest, intermediate and the highest $\mathrm{W} / \mathrm{B}$ ratio, respectively. The pastes were mixed for five minutes and kept in molds $(4 \times 4 \times 16 \mathrm{~cm})$ for three days. All the pastes were stored at $100 \% \mathrm{RH}$ in a desiccator for a month to obtain a high hydration degree of cement while avoiding carbonation. For thirty days, specimens were kept in a desiccator with silica gel. Silica gel reduces RH and removes the water. When

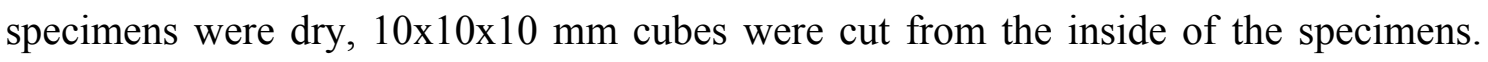
Half of the cubes were stored hermetically (in almost total absence of $\mathrm{CO}_{2}$ ), and the other half were stored in a chamber filled with $\mathrm{CO}_{2}\left(100 \% \mathrm{CO}_{2}\right.$ at atmospheric pressure $)$ in order to get an accelerated carbonation.

\subsection{Accelerated Carbonation}


Specimens were placed into a desiccator and it was filled with commercial $\mathrm{CO}_{2}$. Shortly after $\mathrm{CO}_{2}$ release, condensed water was observed on the walls of the desiccator, as a result of the reaction. Vacuum was applied to remove this water and then more $\mathrm{CO}_{2}$ was introduced. This procedure was repeated until constant weight was reached, indicating that the carbonation reaction was finished.

\subsection{Analytical Methodology}

\subsubsection{Thermal analysis}

Differential thermal analysis (DTA) were conducted using a simultaneous TGA-sDTA 851 Mettler Toledo thermoanalyser, with alumina crucibles, fitted with holed lids, at a $20^{\circ} \mathrm{C} \cdot \mathrm{min}^{-1}$ heating rate, under static air atmosphere, from ambient temperature to $1150^{\circ} \mathrm{C}$.

\subsubsection{XRD analysis}

The mineralogical phases present in the specimens were determined by means of X-Ray Diffraction (XRD) using a Brucker D8 Advance diffractometer, according to the diffraction powder method, with a $\mathrm{CuK}_{\alpha 1}$ radiation and $0.022 \theta$ increment and $1 \mathrm{~s} \cdot \mathrm{step}^{-1}$, sweep from 10 to $80^{\circ} 2 \theta$. The results were compared with the ICDD database.

\subsubsection{Pore Size Distribution}

Pore size distribution was determined by the mercury intrusion porosimetry technique using a Micromeritics Mercury Intrusion Porosimetry AUROPORE 2 9220. Equipment is capable of automatically registering pressure and the software calculates the pore diameter and the intrusion volume from pressure values. 


\subsubsection{Specific Surface Area}

The specific surface area was measured by using a Micromeritics Accelerated Surface Area and Porosimetry ASAP 2000. Surface area was calculated by BET theory.

\section{Results and Discussion}

\subsection{Chemical Composition}

During the carbonation process, the pastes gain $26 \mathrm{~g}$ per mol of $\mathrm{Ca}(\mathrm{OH})_{2}$ carbonated due to the absorption of $\mathrm{CO}_{2}$ and the desorption of $\mathrm{H}_{2} \mathrm{O}$. Thus, the weight of the specimen increases throughout the carbonation process, as shown Fig.1. It is important to point out that all the specimens reach to a constant weight at the same time. This indicates that diffusion in $\mathrm{a}_{2}$ atmosphere is not influenced by the microstructure, however, the opposite is expected when natural carbonation happens. When constant weight is reached, it is necessary to know whether all $\mathrm{Ca}(\mathrm{OH})_{2}$ has been converted to $\mathrm{CaCO}_{3}$. In addition, the polymorph of $\mathrm{CaCO}_{3}$ formed should be determined.

Termogravimetric (TG) analysis (Fig. 2 presents the B pastes as an example) shows that all the pastes were totally carbonated because no weight loss at $\sim 450^{\circ} \mathrm{C}$ attributed to the $\mathrm{Ca}(\mathrm{OH})_{2}$ dehydroxilation has been observed [12]. XRD results (in Fig.3) confirm the absence of $\mathrm{Ca}(\mathrm{OH})_{2}$ (no peaks at $\mathrm{d}$ values: 4.895; 2.619; 1.917 and 1.790, corresponding to $2 \theta$ angles: $18.110 ; 34.215 ; 47.386$ and 50.965$)$ and therefore the complete carbonation of the pastes.

All the peaks shown in Fig. 3 correspond with the calcite polymorph, making calcite the only crystalline polymorph of $\mathrm{CaCO}_{3}$ in the pastes. Thus, the volume increased by $11.2 \%$ due to the carbonation of $\mathrm{Ca}(\mathrm{OH})_{2}$ as shown Table 1 . 


\subsection{Mass Factor}

A mass factor must be applied when comparing the volume of pores and the specific surface area for carbonated and non-carbonated specimens, because these experimental values are given with respect to the mass of the sample and the mass increment due to carbonation should be taken into account. Mass factor could be calculated theoretically by using the percentage of $\mathrm{Ca}(\mathrm{OH})_{2}$ in the paste considering lime content and produced amount during the hydration of calcium silicates. Experimentally, the mass factor can be calculated by dividing the mass of the carbonated specimen by the non-carbonated one. Table 3 shows the experimental mass factor results.

Even though mass factor has not been found in the previous papers studied the changes in microstructure properties produced by the carbonation [1-3], it seems adequate to use this mass factor in order to take into account the change of mass produced as consequence of the carbonation process.

\subsection{Pore structure}

\subsubsection{Porosity}

Table 4 shows the intrudable porosity results of the carbonated and non-carbonated pastes, obtained by mercury intrusion porosimeter. As shown in a previous research [13], the porosity of lime pastes increases in a proportional way with the $\mathrm{W} / \mathrm{B}$ ratio. The same behaviour is also observed in the blended pastes. As demonstrated in Table 4, porosity decreases with the increment of the percentage of cement, due to: the less amount of kneading water employed to get the same workability [14]. Evaluating both 
$\mathrm{W} / \mathrm{B}$ ratio and the binder composition, the latter shows more importance with respect to the porosity by causing higher differences.

With carbonation, porosity decreases in all pastes. The highest decrease is observed for the pastes having the lowest W/B ratio (pastes A), because these pastes have lower porosity and more amount of $\mathrm{Ca}(\mathrm{OH})_{2}$ to be carbonated per volume.

$80 \%$ lime pastes showed lower porosity variation than that of $50 \%$ lime pastes, while a proportional variation of the porosity with respect to the binder composition was expected. This can be explained by taking into account that carbonation of lime pastes $(100 \%)$ gives a marked porosity reduction, as well as carbonation of more rich cement pastes $(50 \%)$. Two opposite non linear trends would give a maximum or a minimum (as indicated by the results for $80 \%$ pastes). The porosity variation in all the pastes is very close to the expected value, $11.2 \%$, which is due to the formation of the calcite polymorph (Table 1).

\subsubsection{Pore Size Distribution}

Mercury intrusion porosimetry technique is based on the Washburn equation (Eq. 6), which assumes that the pores are cylindrical in shape and equally accessible from the outer surface of the specimen:

$$
d=-4 g \cos \theta / P
$$

where $d$ is the diameter of the cylinder, $g$ is the surface tension of mercury, $\theta$ is the contact angle, and $\mathrm{P}$ is the applied pressure. 
Table 5 shows the variation of the volume of pores per gram of paste with the carbonation process. The mass factor was applied in order to compare carbonated and non-carbonated pastes.

The behaviour in this case was the expected, such with the W/B ratio, as with the binder composition. With the W/B ratio in the three binder composition, only a slight variation in the difference $(\Delta)$ between carbonated and non-carbonated pastes can be checked when W/B increases: the variation of porosity $(\Delta)$, porosity expressed as volume of pores/mass $(\mathrm{ml} / \mathrm{g})$, should be approximately constant, due to the mass reference (water content of the mixes are changing). When W/B ratio increases, variation of volume of pores/mass increases slightly. When cement content is increased, variation of volume of pores/mass decreases significantly. This result can be explained as there is less amount of $\mathrm{Ca}(\mathrm{OH})_{2}$ to be carbonated in the pastes rich in cement.

Figure 4 shows the cumulative pore size distribution of different pastes, in which the mass factor has been applied. The increase of the W/B ratio (i.e., the kneading water) does not change the shape of the curve, but shifts the pore size distribution curves towards the higher pore diameters and intruded volume per sample weight. For all paste types, the difference between the pore size distribution of carbonated and noncarbonated pastes is evident. A change in the shape of the pore size distribution curves of $100 \%$ lime pastes, as a consequence of the disappearance of the pores around 0.03 $\mu \mathrm{m}$, is also observed.

The blocking of the smaller pores (in this case smaller than $0.003 \mu \mathrm{m}$ ) is because the water condenses better in the smaller pores as explain by Kelvin equation (Eq.7). Therefore, the precipitation of $\mathrm{CaCO}_{3}$ preferably takes place in the smaller pores. Besides, the osmotic pressure created in these small pores improves the precipitation of the $\mathrm{CaCO}_{3}[15]$. 


$$
-\operatorname{Ln}\left(p / p_{s}\right)=2 \cdot \gamma \cdot V / R \cdot T \cdot r
$$

where, $p$ is the water pressure, $p_{s}$ is the water saturated pressure at temperature $T, \gamma$ is the specific surface energy of water, $\mathrm{V}$ is the molar volume of water, $\mathrm{R}$ is the gas constant, and $r$ is the capillary radius. In general, carbonation moves the pore size distribution curve towards the smaller pore diameters and total volume of pores per gram of paste.

Diamond [16] introduced the "threshold diameter", the pore diameter that corresponds to a pressure above which the greater portion of the intrusion takes place, to explain the "pore blockage" concept. The threshold diameter is a characteristic property of the pore structure and therefore varies with the microstructure of the material. The approximated values of the threshold diameter for each paste are given in Table 6 . Threshold diameter increases with W/B ratio both in carbonated and non-carbonated pastes, whereas it reduces with carbonation as a result of reduced pore size for constant $\mathrm{W} / \mathrm{B}$ ratio. The variation due to the carbonation is smaller than the variation due to the $\mathrm{W} / \mathrm{B}$ ratio.

Fig. 5, shows the cumulative curves of the intrusion differences of the non-carbonated and the carbonated pastes. From Fig. 5, it can be observed that the influence of carbonation on the microstructure is similar for the pastes having the same composition but significantly different for the ones having varying $\mathrm{W} / \mathrm{B}$ ratios. When $\mathrm{W} / \mathrm{B}$ ratio increases, pores are shifted towards the larger diameters. The slope of the curves is an indication of the kind of modification takes place in the microstructure. If the slope is positive, the porosity corresponding to the size range of pores increases due to the increase of number of pores at this size. On the other hand, if the slope is negative, a 
reduction of the number of pores at this size range of pores has taken place. From the curves, several behaviors can be differentiated.

As Fig. 5 shown, below $0.3 \mu \mathrm{m}$ practically all the slopes are negative, but with different intensities. In 100\% lime pastes (Fig. 5 (A)), a high slope between 0.01 and $0.04 \mu \mathrm{m}$ indicates a reduction of this size of pores. There is no positive slope after this negatives slopes that indicates the increment of other pore size, thus, these pores are blocked by $\mathrm{CaCO}_{3}$ after carbonation. In the $80 \%$ lime pastes, practically no slope changes can be detected below $0.1 \mu \mathrm{m}$. This fact can be related to the unexpected observed behaviour in porosity changes. As discussed in 4.3 .1 section, $80 \%$ pastes show the lowest porosity variation between carbonated and non-carbonated state. Fig. 5 (B) shows that intermediate porosity $(\sim 0.1-0.001 \mu \mathrm{m})$ does not change for $80 \%$ pastes.

A microstructural reason, due to the distribution of the low amount of cement into the lime could be proposed to give a possible explanation to this behaviour. However, more research is necessary to confirm this supposition. In the $50 \%$ lime pastes, a marked slope takes place between 0.2 and $0.02 \mu \mathrm{m}$.

In all the pastes, around $1 \mu \mathrm{m}$ (shifting toward smaller diameters with the increment of cement in the paste) there is a sharp increase followed by a decrease in the plots. This indicates that a reduction of the pore size corresponding to the main pore size [13] takes place, decreasing the population of the initial main pore size (negative slope), and increasing the population of the new main pore size (positive slope). It should be pointed out that the intensity of the modification of pore diameters is proportional to the slope of the curve.

The shape of the curves changes depending on the composition of the paste (i.e., the cement amount). The behaviour changes as a function of the binder composition. Therefore, while in the lime pastes the biggest modification of the microstructure takes 
place below $0.03 \mu \mathrm{m}$, in the $50 \%$ lime pastes the highest modification takes place between 0.2 and $0.02 \mu \mathrm{m}$. For the $80 \%$ lime pastes the modification is very small, with very small slopes, as previously discussed.

\subsubsection{Surface Fractal Dimension}

Diamond [17] defined the materials like pore fractal objects as dense objects within which a distribution of holes or pores with a fractal structure exists. Bernal et al [18] explained and compared several methods to calculate surface fractal dimension. In this study, Zhang and Li model (Eq. 8) was applied to the mercury intrusion porosimetry data to obtain correlation coefficients. The Zhang and Li model was derived from thermodynamic considerations and dimensional analysis [19]:

$$
Q_{n}=-\sum_{i=1}^{n} \overline{P_{i}} \Delta V_{i} \propto r_{n}^{2-D} V_{n}^{D / 3}=W_{n}
$$

where $\mathrm{P}$ is the pressure applied, $\mathrm{V}$ is the volume, $\mathrm{r}$ is the radius and $\mathrm{D}$ is the surface fractal dimension. For lime pastes, the model was applied to the pores ranging from the main pore diameter (around $0.5 \mu \mathrm{m}$ ) to $0.03 \mu \mathrm{m}$ since both carbonated and noncarbonated pastes have pores at this range. For $80 \%$ and $50 \%$ lime pastes, the range was extended to $0.02 \mu \mathrm{m}$ diameter pores. According to Pfeifer and Obert [20], in order to accept an experimental fractal dimension, the pore diameter range used to calculate the fractal dimension should expand one decade or more. This requirement has been fulfilled in the present work.

Surface fractal dimension decreases with carbonation process except $80 \%$ pastes. This result can be explained by taking the porosity curves of $80 \%$ pastes into consideration 
(see 4.3.2). $100 \%$ pastes that are totally carbonated practically do not change their $\mathrm{D}_{\mathrm{S}}$ when W/B increases, as stated in a previous work by our research group [13]. The decrease of the variation is small, because the range of pores studied is the range that is less affected by carbonation as shows Fig. 5 (A). The range of pores in which the highest modification of the microstructure takes place can not be studied because, at least in lime pastes, the pores are blocked as consequence of the deposition of calcite.

Bernal et al. [17] used the surface fractal dimension to differentiate weathered and unweathered stones. They concluded that the surface fractal dimension of the porosity system increases when the stones are weathered. Carbonation process can be considered as an opposite process, the formation of a stone, in which the complexity of the surface decreases.

\subsection{Specific Surface Area}

Johannesson and Utgenannt [2] studied the effect of carbonation on the specific surface area of cement mortar using BET theory. They concluded that the specific surface area of the non-carbonated mortar is higher than that of the well-carbonated one. However, the difference was very small (8\%). In this study, the experimental mass factors given in Table 3 are used to compare the specific surface area between carbonated and noncarbonated pastes. (since specific surface area is referred to the mass of sample under study.)

As Table 8 shows, the change of the specific surface area with carbonation is quite different as a function of the composition of the paste. Before carbonation, surface area does not seem to be influenced by the W/B ratio and the surface area of lime paste is the highest. After carbonation, the specific surface area seems to be affected by both W/B ratio and the percentage of cement in the paste. Specific surface area of lime pastes 
decreases with carbonation process. The decrease is higher for higher W/B ratios. This decrease in specific surface area can be attributed to the reduction of the smallest pores in the system (Fig. 4 (A)) due to the crystallization of calcite crystals in the smallest pores that are blocked. The behavior of the carbonated blended pastes is totally opposite. Carbonation increases the specific surface area: the higher the W/B ratio, the higher the increase of the specific surface area. Blended pastes of lime and cement includes two kinds of pores; capillary pores $(10 \mu \mathrm{m}-0.005 \mu \mathrm{m})$, that can be studied by MIP, and the gel pores $(<0.005 \mu \mathrm{m})$, that are associated to the $\mathrm{C}-\mathrm{S}-\mathrm{H}$ gel, can not be studied by MIP [19]. The increment of the specific surface area in blended pastes can be due to the opening of gel pores as a consequence of the carbonation. It is known that when $\mathrm{C}-\mathrm{S}-\mathrm{H}$ carbonates its $\mathrm{Ca} / \mathrm{Si}$ ratio gets lower and it becomes highly porous, approaching hydrous silica. Therefore the surface area is expected to increase due to this change, or as consequence of microcracking created due to the expansion of some products of the carbonation process [21].

\section{Conclusions}

Porosity and pore structure changes due to the carbonation shown: a porosity decreases around $10 \%$ and a pore size distribution shifted towards smaller pores. The volumetric decrease of pores was proportional to the amount of carbonated $\mathrm{Ca}(\mathrm{OH})_{2}$.

The cumulative intrusion curves of the difference between the cumulative intrusion of non-carbonated and carbonated pastes shown owing to the carbonation: i) a reduction of pore size of $1 \mu \mathrm{m}$; ii) a decrease of smaller pores: for lime pastes the higher modification takes place between pore diameters of $0.01 \mu \mathrm{m}$ and $0.03 \mu \mathrm{m}$, and in the $50 \%$ pastes between the diameters of $0.2 \mu \mathrm{m}$ and $0.02 \mu \mathrm{m} .80 \%$ pastes show no change between $0.1-0.001 \mu \mathrm{m}$ pore diameter, as confirms lowest porosity changes and $\mathrm{D}_{\mathrm{S}}$ 
between carbonated and non-carbonated state. Curves are shifted towards smaller diameters with decreasing $\mathrm{W} / \mathrm{B}$ ratios.

The surface fractal dimension seems to decrease with the carbonation process, verifying that the carbonation process is like a stone forming process. Therefore, carbonation leads to a less complex surface.

With carbonation, the specific surface area decreases in lime pastes as a consequence of the decrease of the smaller porosity $(<0.03 \mu \mathrm{m})$, but increases when there is cement in the paste, possibly, due to the deterioration of C-S-H (opening of gel pores) and the appearance of microcracking.

\section{Acknowledgements}

The present study was the result of a brief stay in the University of Illinois in Urbana Champaign supported by the "Ministerio de Educación Cultura y Deporte" of Spain. We also acknowledge support from the Portland Cement Association for Beril BicerSimser's participation. Additional project support at UIUC was provided by the Center for Advanced Cement-Based Materials.

\section{References}

[1] V. T. Ngala, Cem. Concr. Res. 27 (7) (1997) 995-1007.

[2] B. Johannesson, P. Utgenannt, Cem. Concr. Res. 31 (2001) 925-931.

[3] Y.F. Houst, Cem. Concr. Res. 24 (1994) 1165-1176.

[4] W.P.S. Dias, Cem. Concr. Res. 30 (2000) 1255-1261.

[5] C. Rodríguez-Navarro, O. Cazalla, The Royal Society 458 (2002) 2261-2273.

[6] M. Fernández Bertos, S.J.R Simons, J. Hazard Mater. 112 (2004) 193-205.

[7] K. Van Balen, D. Van Gemert, Mater. Struct. 27 (1994) 393-398. 
[8] Y.S. Han, G. Hadiko, M. Fuji, M Takahashi, J Crystal Growth 276 (2005) 541548.

[9] http://webmineral.com

[10] UNE-EN 459-1, Building Lime: Part 1. Definition, specification and conformity criteria, 1996.

[11] UNE 80.301:1996 Cementos comunes: Composición especificaciones y criterios

[12] T.L. Webb, J.E. Krüger, Carbonates, in: R.C. Mc Kenzie (Ed.), Differential Thermal Analysis, Academic Press, London, 1970, pp. 238-266.

[13] M. Arandigoyen, J.L Pérez Bernal, M.A Bello López, J.I. Alvarez, Appl. Surf. Sci. (2005). (available on line in Sciencedirect.com)

[14] J. Lanas, J.I. Alvarez, Cem. Concr. Res. 33 (2003) 1867-1876.

[15] O. Cazalla, Morteros de cal, Aplicación en el patrimonio histórico, Unpublished $\mathrm{PhD}$ thesis (in Spanish), Universidad de Granada, Granada, 2002.

[16] S. Diamond, Cem. Concr. Res. 30 (2000) 1517-1525.

[17] J.L. Pérez Bernal, M.A. Bello López, Appl. Surf. Sci. 161 (2000) 47-53.

[18] J.L. Pérez Bernal, M.A. Bello López, Appl. Surf. Sci. 185 (2001) 99-107.

[19] B.Zhang, S. Li, Ind. Eng. Chem. Res. 34 (1995) 1383-1386

[20] P. Pfeifer, M. Obert, in: D. Avnir (Ed.), The Fractal Approach to Heterogeneous Chemistry, Wiley, New York, 1989, p.16.

[21] H.F.W. Taylor, La química de los cementos, (1978) Ed. URMO. 


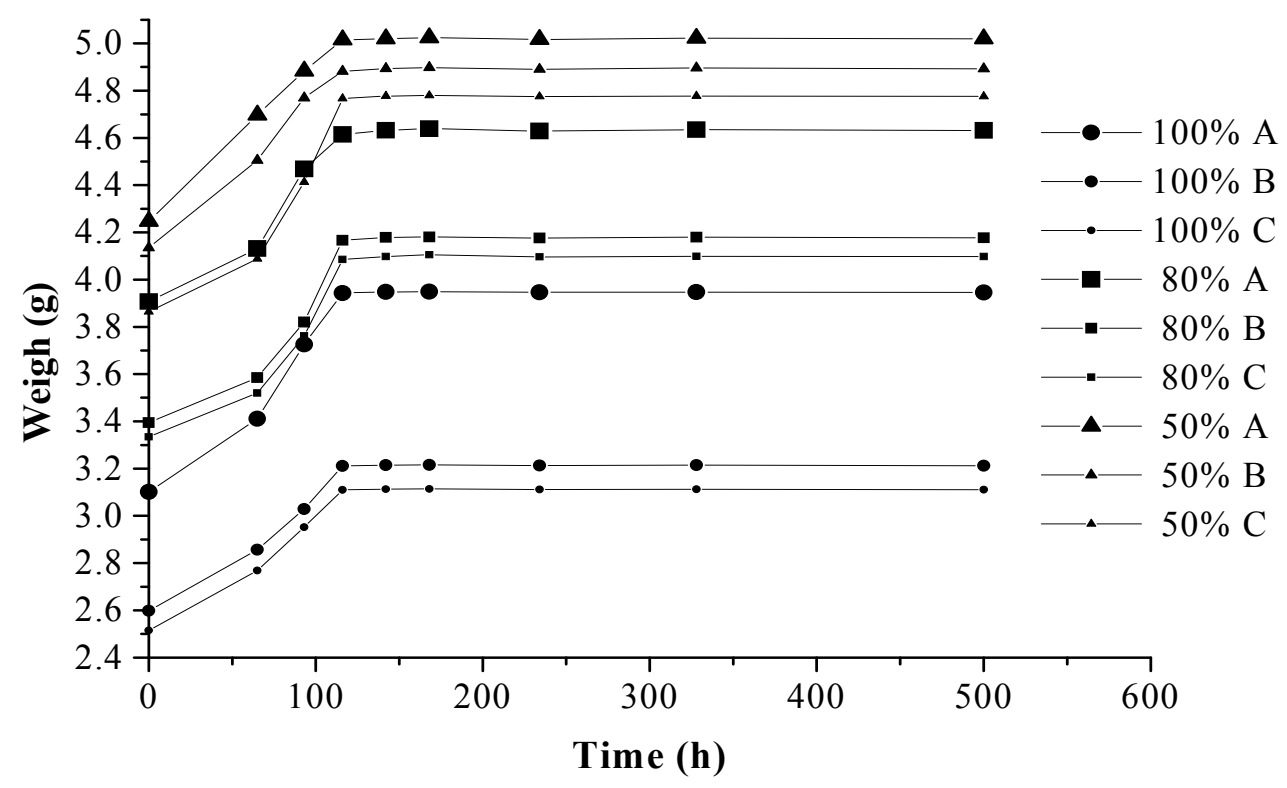

Figure 1. The weight change of the pastes during carbonation. 


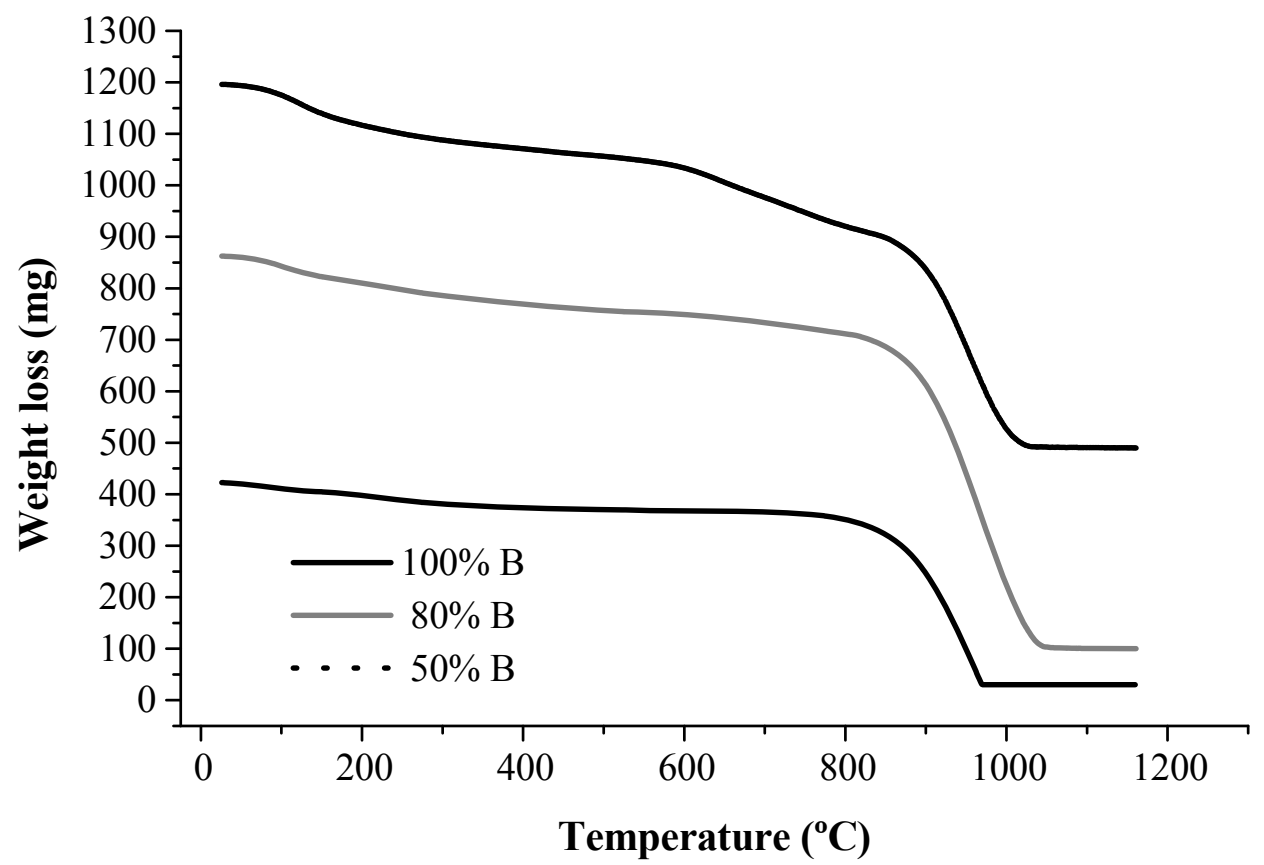

Figure 2. TG of the B pastes with different binder compositions. 


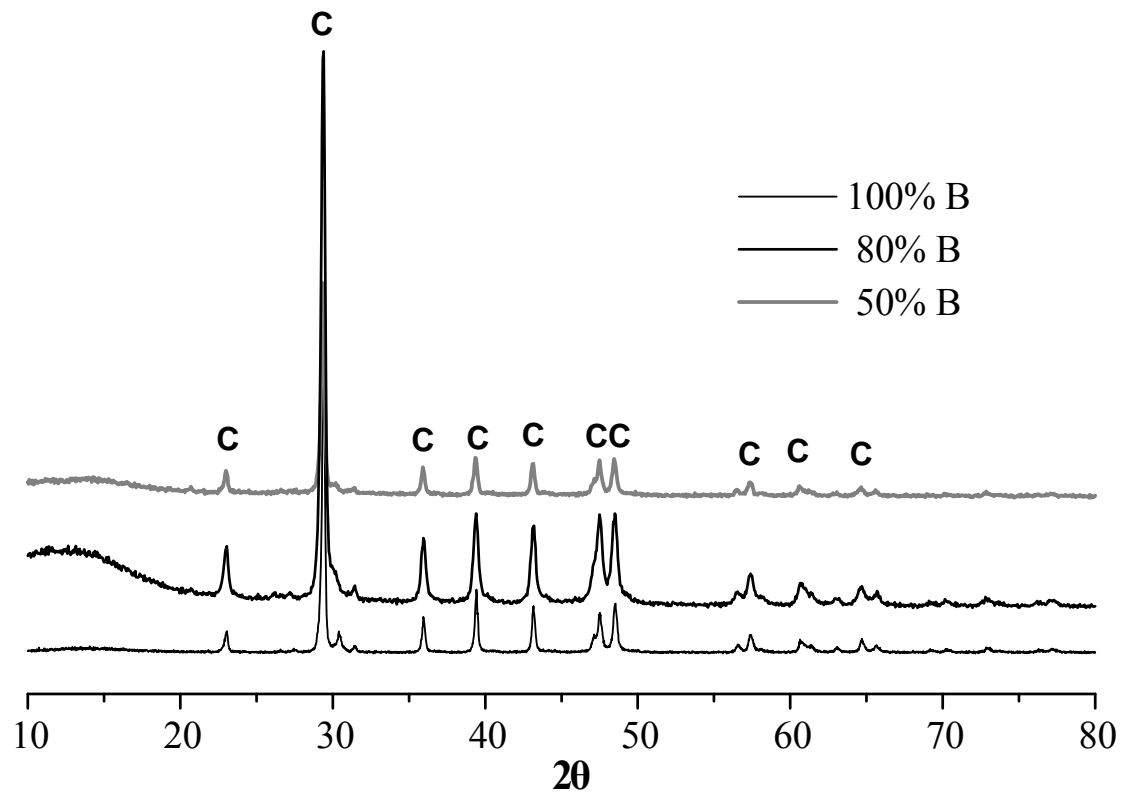

Figure 3. X-ray diffraction for the B pastes (C: Calcite (ICDD 05-0586)). 


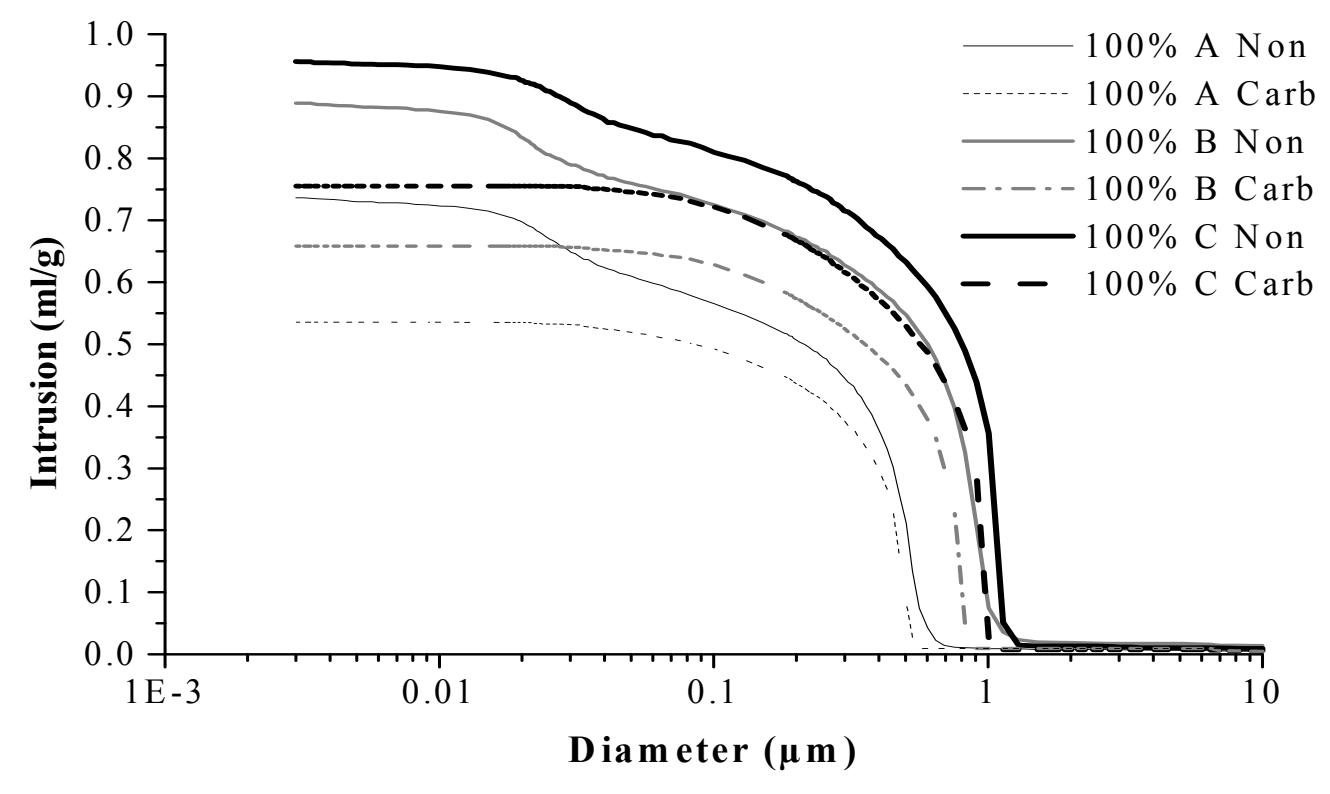

(A)

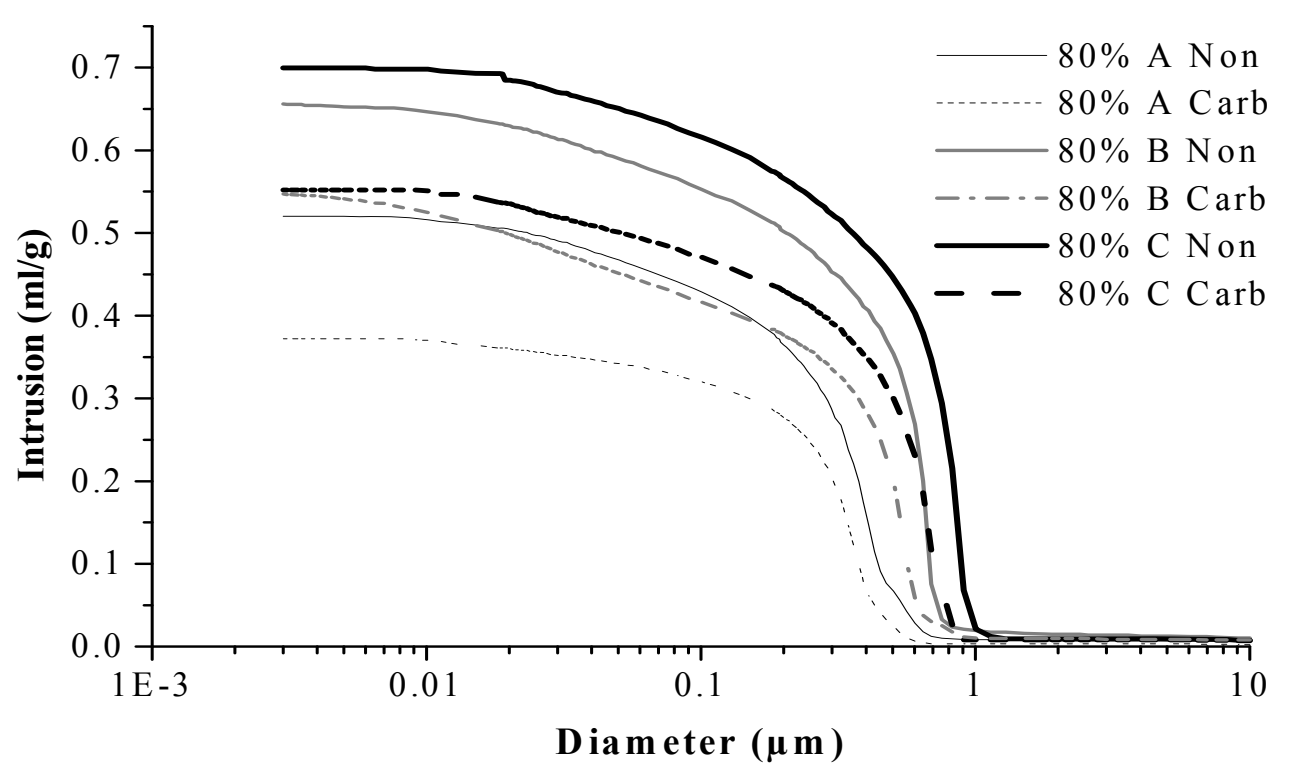

(B) 


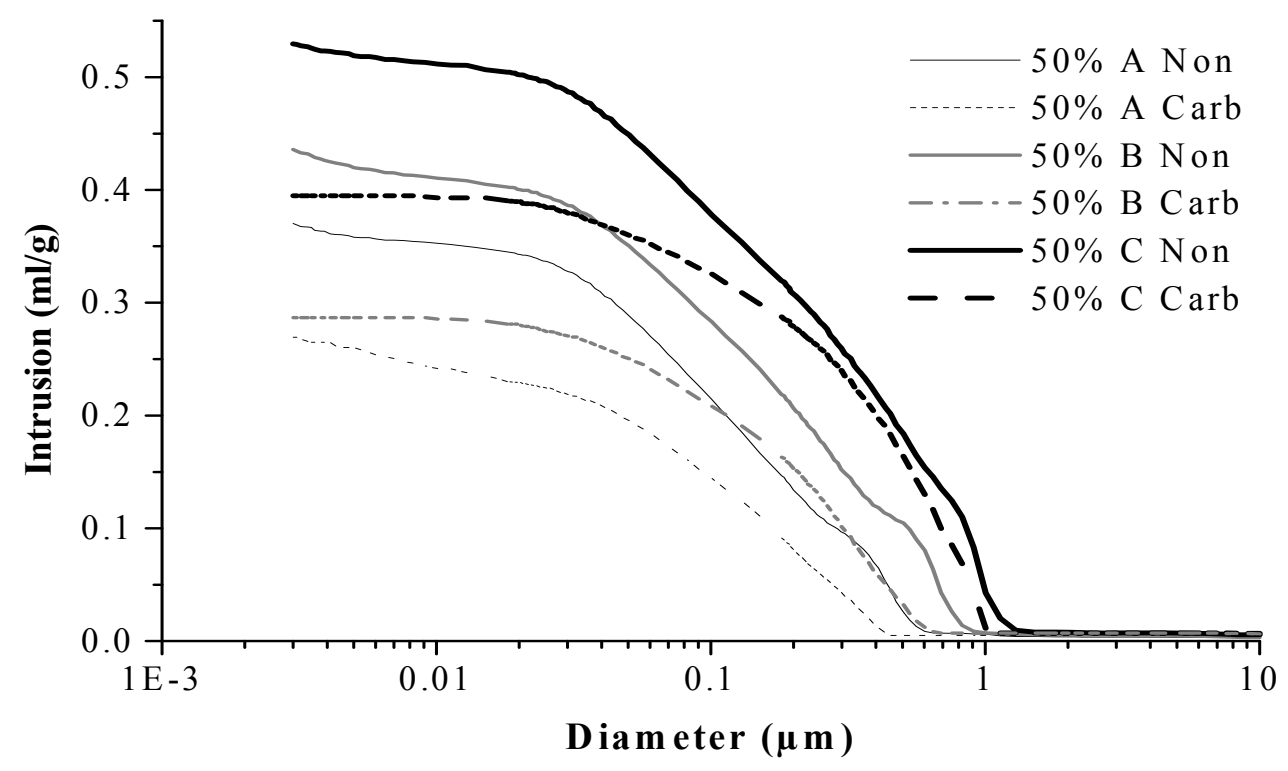

(C)

Figure 4. Pore size distribution for carbonated and non-carbonated pastes: (A) $100 \%$ Lime pastes, (B) $80 \%$ Lime Pastes, (C) 50\% Lime Pastes. 


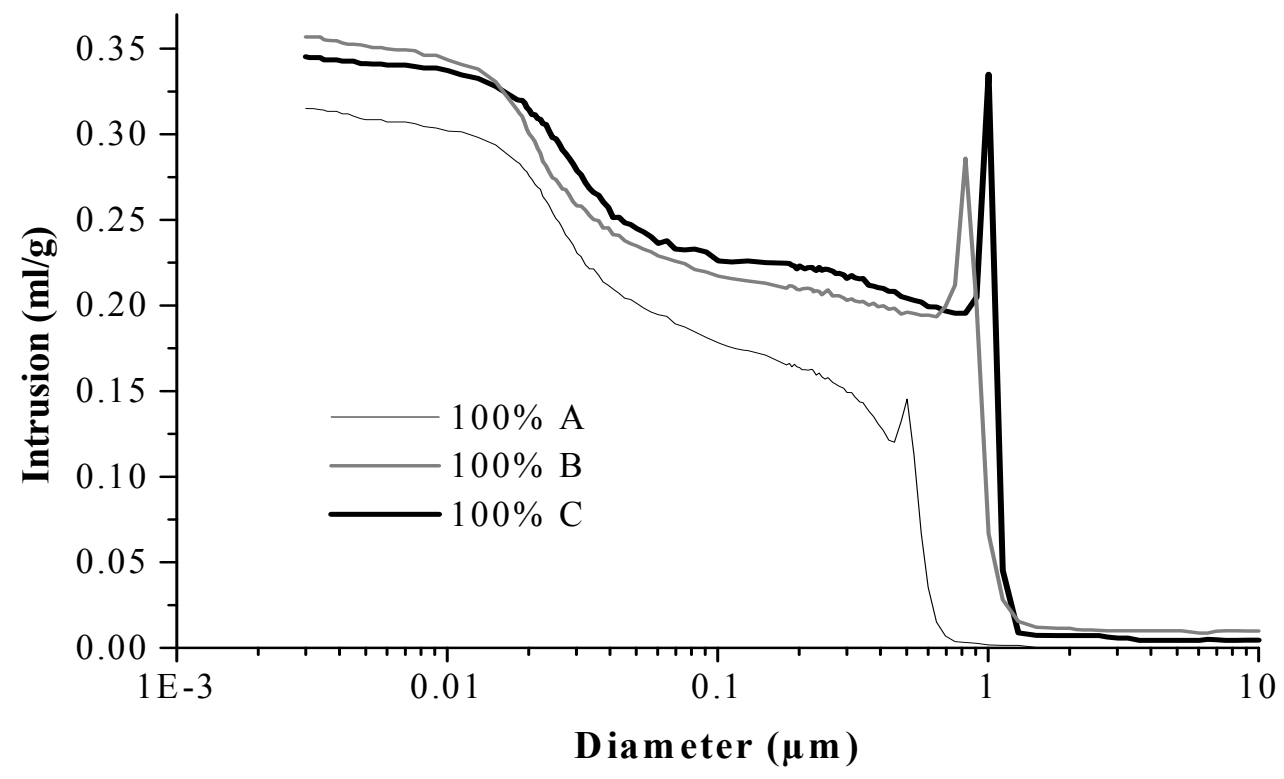

(A)

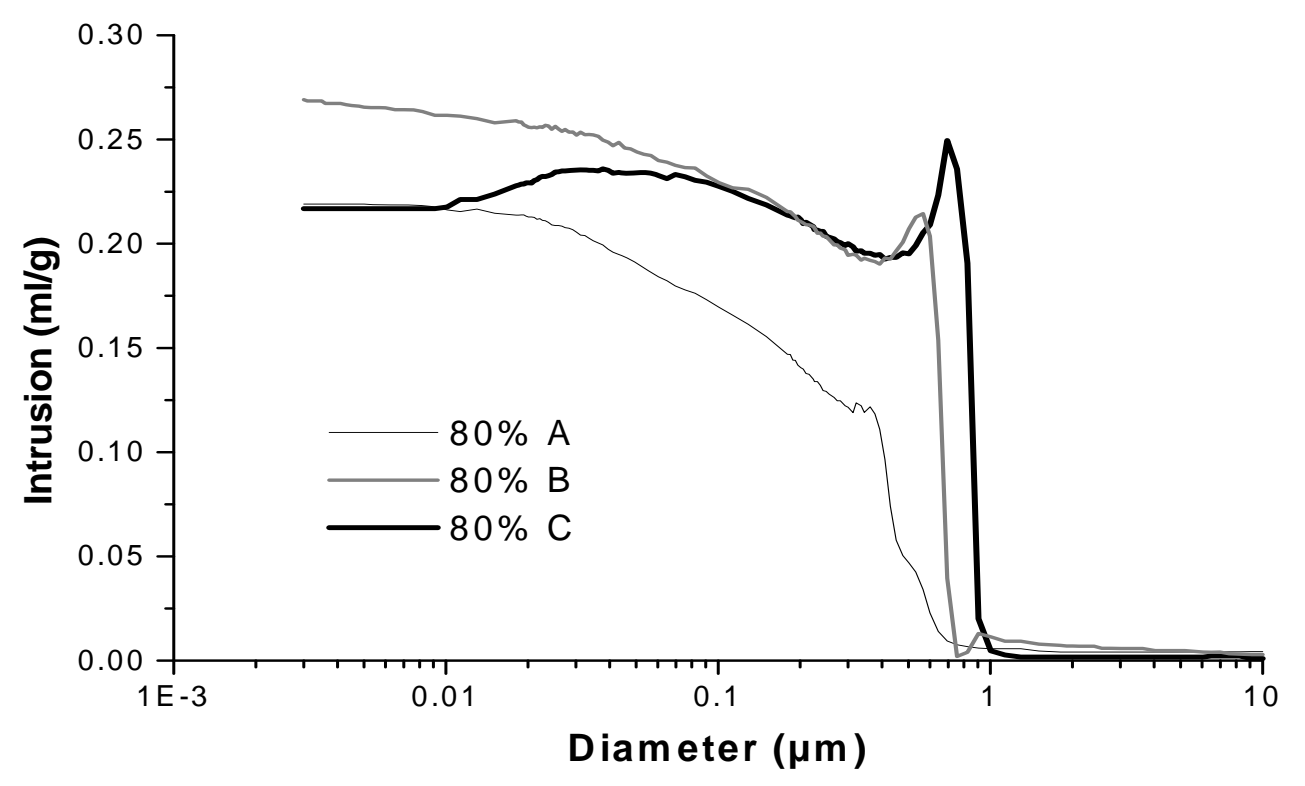

(B) 


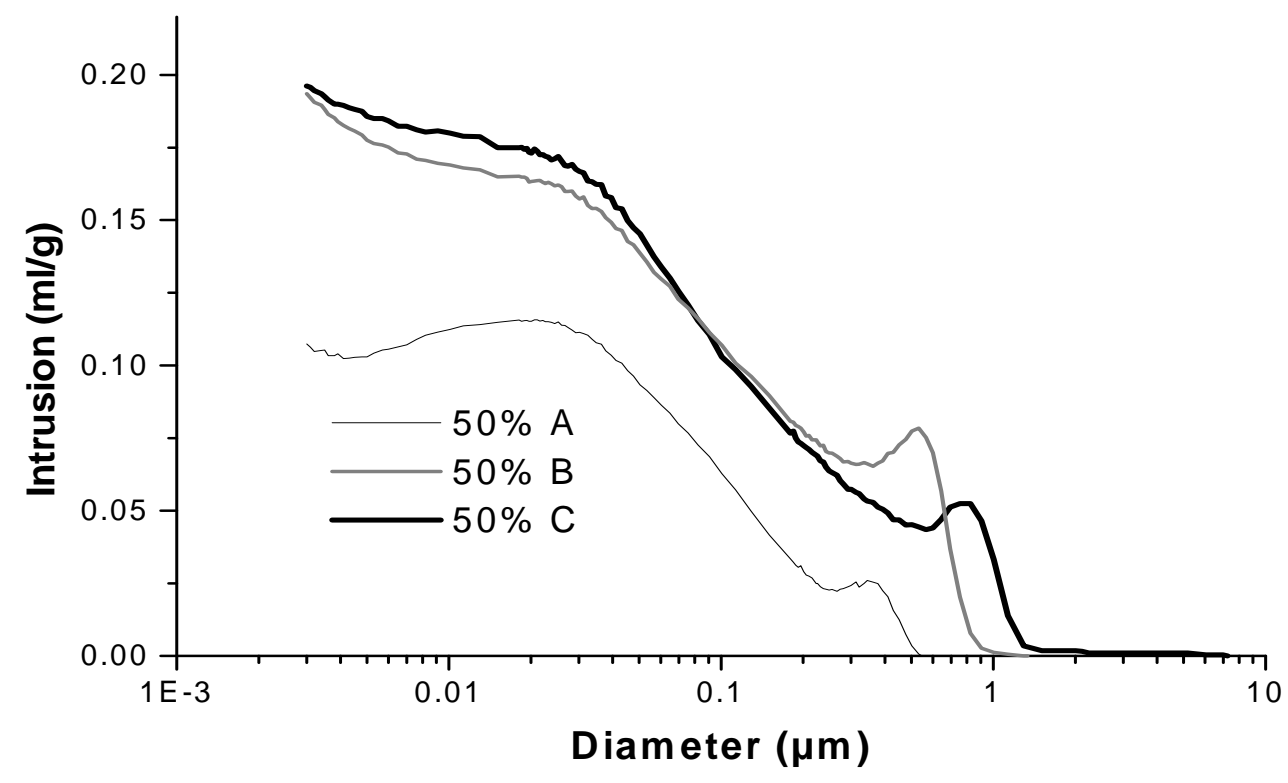

(C)

Figure 5. The cumulative difference of the intrusion of the non-carbonated and carbonated pastes having different W/B ratios: (A) 100\% lime paste, (B) 80\% lime paste, (C) 50\% lime paste. 
Table 1. Properties of the minerals that can be involved in the carbonation process [9].

\begin{tabular}{|c|c|c|c|c|}
\hline Mineral & $\begin{array}{c}\text { Density } \\
\left(\mathbf{g} \cdot \mathbf{c m}^{-\mathbf{3}} \mathbf{)}\right.\end{array}$ & $\begin{array}{c}\text { Molar Volume } \\
\left(\mathbf{c m}^{\mathbf{3}} \mathbf{)}\right.\end{array}$ & Crystal Shape & $\begin{array}{c}\text { Variation of } \\
\text { Volume }\end{array}$ \\
\hline Portlandite & 2.23 & 33.20 & Laminar & --- \\
\hline Calcite & 2.71 & 36.93 & Prismatic & $11.2 \%$ \\
\hline Aragonite & 2.93 & 34.16 & Fibrous & $2.9 \%$ \\
\hline Vaterite & 2.54 & 39.40 & Spherical & $18.7 \%$ \\
\hline
\end{tabular}


Table 2. Composition of the pastes.

\begin{tabular}{|l|c|c|c|c|c|c|c|c|c|}
\hline & $\mathbf{1 0 0} \%$ & $\mathbf{1 0 0 \%}$ & $\mathbf{1 0 0 \%}$ & $\mathbf{8 0 \%}$ & $\mathbf{8 0 \%}$ & $\mathbf{8 0 \%}$ & $\mathbf{5 0 \%}$ & $\mathbf{5 0 \%}$ & $\mathbf{5 0 \%}$ \\
$\mathbf{A}$ & $\mathbf{B}$ & $\mathbf{C}$ & $\mathbf{A}$ & $\mathbf{B}$ & $\mathbf{C}$ & $\mathbf{A}$ & $\mathbf{B}$ & $\mathbf{C}$ \\
\hline \% Lime & 100 & 100 & 100 & 80 & 80 & 80 & 50 & 50 & 50 \\
\hline \% Cement & 0 & 0 & 0 & 20 & 20 & 20 & 50 & 50 & 50 \\
\hline W/B ratio & 0.90 & 1.10 & 1.30 & 0.70 & 0.85 & 1.00 & 0.55 & 0.65 & 0.75 \\
\hline
\end{tabular}


Table 3. Experimental mass factor for each group of pastes.

\begin{tabular}{|c|c|c|c|}
\hline $\begin{array}{c}\text { Lime amount in the } \\
\text { binder fraction }\end{array}$ & $\mathbf{A}$ & $\mathbf{B}$ & $\mathbf{C}$ \\
\hline $\mathbf{1 0 0 \%}$ & 1.27 & 1.24 & 1.24 \\
\hline $\mathbf{8 0 \%}$ & 1.24 & 1.23 & 1.23 \\
\hline $\mathbf{5 0 \%}$ & 1.18 & 1.18 & 1.18 \\
\hline
\end{tabular}


Table 4. Open porosity of carbonated and non-carbonated pastes.

\begin{tabular}{|c|c|c|c|c|}
\hline \multirow{2}{*}{$\begin{array}{c}\text { Lime Content } \\
(\%)\end{array}$} & \multicolumn{3}{c|}{ Porosity (MIP) (\%) } \\
\cline { 3 - 5 } & Non & 63.9 & A & C \\
\hline \multirow{3}{*}{$\mathbf{1 0 0 \%}$} & Carb & 49.9 & 68.9 & 69.4 \\
\cline { 2 - 5 } & $\Delta$ & $\mathbf{- 1 4 . 0}$ & $\mathbf{- 1 3 . 2}$ & $\mathbf{- 1 0 . 6}$ \\
\hline \multirow{3}{*}{$\mathbf{8 0} \%$} & Non & 53.5 & 60.1 & 60.3 \\
\cline { 2 - 5 } & Carb & 40.6 & 50.3 & 51.4 \\
\cline { 2 - 5 } & $\Delta$ & $\mathbf{- 1 2 . 9}$ & $\mathbf{- 9 . 8}$ & $\mathbf{- 8 . 9}$ \\
\hline \multirow{3}{*50\%}{} & Non & 46.4 & 47.7 & 55.2 \\
\cline { 2 - 5 } & Carb & 31.9 & 34.8 & 42.6 \\
\cline { 2 - 5 } & $\Delta$ & $\mathbf{- 1 4 . 1}$ & $\mathbf{- 1 2 . 9}$ & $\mathbf{- 1 2 . 6}$ \\
\hline
\end{tabular}


Table 5. Volume of pores per gram of paste for carbonated and non-carbonated pastes.

\begin{tabular}{|c|c|c|c|c|}
\hline \multirow{2}{*}{ Lime Content (\%) } & \multicolumn{3}{|c|}{$\begin{array}{c}\text { Volume of pores/Mass } \\
\text { (ml/g) }\end{array}$} \\
\cline { 3 - 5 } & & $\mathrm{A}$ & $\mathrm{B}$ & $\mathrm{C}$ \\
\hline \multirow{3}{*}{$\mathbf{1 0 0 \%}$} & Non & 0.736 & 0.889 & 0.956 \\
\cline { 2 - 5 } & Carb & 0.536 & 0.658 & 0.755 \\
\cline { 2 - 5 } & $\Delta$ & $\mathbf{- 0 . 2 0 0}$ & $\mathbf{- 0 . 2 3 1}$ & $\mathbf{- 0 . 2 0 1}$ \\
\hline \multirow{3}{*}{$80 \%$} & Non & 0.520 & 0.656 & 0.700 \\
\cline { 2 - 5 } & Carb & 0.372 & 0.476 & 0.552 \\
\cline { 2 - 5 } & $\Delta$ & $\mathbf{- 0 . 1 4 8}$ & $\mathbf{- 0 . 1 8 0}$ & $\mathbf{- 0 . 1 4 8}$ \\
\hline \multirow{3}{*}{$50 \%$} & Non & 0.370 & 0.436 & 0.529 \\
\cline { 2 - 5 } & Carb & 0.269 & 0.287 & 0.395 \\
\cline { 2 - 5 } & $\Delta$ & $\mathbf{- 0 . 1 0 1}$ & $\mathbf{- 0 . 1 4 9}$ & $\mathbf{- 0 . 1 3 4}$ \\
\hline
\end{tabular}

(a) The mass factor has been applied. 
Table 6. Threshold diameter for each one of the pastes

\begin{tabular}{|c|c|c|c|c|}
\hline \multirow{2}{*}{ Lime Content (\%) } & \multicolumn{3}{|c|}{ Threshold Diameter $(\boldsymbol{\mu m})$} \\
\cline { 2 - 5 } & & A & B & C \\
\hline \multirow{3}{*}{$\mathbf{1 0 0} \%$} & Non & 0.64 & 1.13 & 1.29 \\
\cline { 2 - 5 } & Carb & 0.53 & 0.90 & 1.13 \\
\cline { 2 - 5 } & $\Delta$ & $\mathbf{- 0 . 1 1}$ & $\mathbf{- 0 . 2 3}$ & $\mathbf{- 0 . 1 6}$ \\
\hline \multirow{3}{*}{$8 \%$} & Non & 0.64 & 0.75 & 1.0 \\
\cline { 2 - 5 } & Carb & 0.56 & 0.64 & 0.9 \\
\cline { 2 - 5 } & $\Delta$ & $\mathbf{- 0 . 0 8}$ & $\mathbf{- 0 . 1 1}$ & $\mathbf{- 0 . 1 0}$ \\
\hline \multirow{3}{*}{$\mathbf{5 0} \%$} & Non & 0.56 & 0.75 & 1.29 \\
\cline { 2 - 5 } & Carb & 0.39 & 0.59 & 1.00 \\
\cline { 2 - 5 } & $\Delta$ & $\mathbf{- 0 . 1 7}$ & $\mathbf{- 0 . 1 6}$ & $\mathbf{- 0 . 2 9}$ \\
\hline
\end{tabular}


Table 7. Values of surface fractal dimension before and after carbonation.

\begin{tabular}{|c|c|c|c|c|}
\hline \multirow{2}{*}{ Lime Content (\%) } & \multicolumn{3}{|c|}{ Surface fractal dimension } \\
\cline { 2 - 5 } & & A & B & C \\
\hline \multirow{3}{*}{$\mathbf{1 0 0 \%}$} & Non & 2.43 & 2.39 & 2.39 \\
\cline { 2 - 5 } & Carb & 2.36 & 2.33 & 2.34 \\
\cline { 2 - 5 } & $\boldsymbol{\Delta}$ & $\mathbf{- 0 . 0 7}$ & $\mathbf{- 0 . 0 6}$ & $\mathbf{- 0 . 0 5}$ \\
\hline \multirow{3}{*}{$\mathbf{8 0} \%$} & Non & 2.54 & 2.41 & 2.41 \\
\cline { 2 - 5 } & Carb & 2.45 & 2.43 & 2.41 \\
\cline { 2 - 5 } & $\boldsymbol{\Delta}$ & $\mathbf{- 0 . 0 9}$ & $\mathbf{+ 0 . 0 2}$ & $\mathbf{0 . 0 0}$ \\
\hline \multirow{3}{*}{$\mathbf{5 0 \%}$} & Non & 2.68 & 2.66 & 2.64 \\
\cline { 2 - 5 } & Carb & 2.65 & 2.56 & 2.55 \\
\cline { 2 - 5 } & $\boldsymbol{\Delta}$ & $\mathbf{- 0 . 0 3}$ & $\mathbf{- 0 . 1 0}$ & $\mathbf{- 0 . 0 9}$ \\
\hline
\end{tabular}


Table 8. Values of specific surface area for carbonated and non-carbonated pastes.

\begin{tabular}{|c|c|c|c|c|}
\hline \multirow[b]{2}{*}{ Specimen } & \multicolumn{2}{|c|}{ Specific Surface Area $\left(\mathrm{m}^{2} / \mathrm{g}\right)^{\mathrm{a}}$} & \multicolumn{2}{|c|}{ Difference (Non - Carb) } \\
\hline & $\begin{array}{c}\text { Non- } \\
\text { Carbonated }\end{array}$ & Carbonated & $\left(\mathrm{m}^{2} / \mathrm{g}\right)^{\mathrm{a}}$ & $\%$ \\
\hline $100 \% \mathrm{~A}$ & 21.19 & 15.03 & -6.16 & -29.06 \\
\hline $100 \% \mathrm{~B}$ & 20.89 & 11.36 & -9.53 & -45.62 \\
\hline $100 \% \mathrm{C}$ & 21.99 & 9.87 & -12.12 & -55.11 \\
\hline $80 \% A$ & 15.19 & 20.97 & 5.78 & 38.04 \\
\hline $80 \%$ B & 16.10 & 22.87 & 6.77 & 42.01 \\
\hline $80 \% \mathrm{C}$ & 14.62 & 23.68 & 9.07 & 62.03 \\
\hline $50 \%$ A & 15.19 & 38.69 & 23.50 & 154.71 \\
\hline $50 \%$ B & 17.08 & 41.38 & 24.30 & 142.26 \\
\hline $50 \% \mathrm{C}$ & 16.06 & 42.26 & 26.19 & 163.07 \\
\hline
\end{tabular}

(a) The mass factor has been applied. 